\title{
Erratum to: Proximal tibial osteophytes \\ and their relationship with the height of the tibial spines of the intercondylar eminence: paleopathological study
}

Mohammad Reza Hayeri • Masoud Shiehmorteza •

Debra J. Trudell • Tori Heflin • Donald Resnick

Published online: 7 March 2010

(C) ISS 2010

Erratum to: Skeletal Radiol

DOI 10.1007/s00256-009-0838-z

Unfortunately, T.Heflin's name was erroneously spelled in the original list of authors. It should read T.Heflin.

The online version of the original article can be found under http://dx. doi.org/10.1007/s00256-009-0838-z.

M. R. Hayeri $(\bowtie)$

Department of Radiology, Children's National Medical Center,

111 Michigan Avene NW,

Washington, DC 20010, USA

e-mail:mr_hayeri@yahoo.com

M. Shiehmorteza $\cdot$ D. J. Trudell $\cdot$ D. Resnick

Department of Radiology, University of California San Diego,

San Diego, CA, USA

T. Heflin

Museum of Man San Diego,

San Diego, CA, USA 